\title{
Chikungunya e sua abordagem transversal no ensino de ciências naturais
}

\begin{abstract}
O vírus CHIKV, que promove a doença Chikungunya, é transmitido por mosquitos das espécies Aedes aegypti e albopictus. Esses mosquitos têm preferência por locais quentes e úmidos como o Brasil que é um país tropical. Com a chegada do vírus em nosso país, diversos casos de infecção e óbitos pela doença foram identificados. Desde então, o Ministério da Saúde junto com outras secretarias do Estado, como o Ministério da Educação, promove estratégias de combate ao vetor da doença. Nesse aspecto, as escolas colaboram com estratégias educativas que também promovem o combate ao vetor da Chikungunya. Essa pesquisa teve como objetivo avaliar o conhecimento dos alunos do terceiro ano do ensino médio de três colégios estaduais de Macaé/RJ sobre o tema Chikungunya. Ela foi desenvolvida em três escolas da rede pública do município de Macaé, com a apliçąão de um questionário composto por 8 perguntas que abordaram aspectos de conhecimento específico sobre Chikungunya. Um total de 65 estudantes foram entrevistados. Cerca de $44 \%$ dos estudantes identificaram corretamente o agente patogênico da Chikungunya, $88 \%$ identificaram corretamente o vetor transmissor da doença, $81 \%$ conhecem os processos que contribuem para a proliferação do vetor. Por outro lado, cerca de $48 \%$ não reconhecem os principais sintomas da doença, $23 \%$ não sabem que a doença pode causar a morte e $47 \%$ não reconhecem a fase em que o vetor transmite a doença. Concluímos que, apesar dos estudantes entrevistados terem apresentado conhecimento sobre alguns assuntos, eles ainda possuem uma defasagem em alguns pontos sobre o tema Chikungunya, sendo necessário que o tema seja melhor trabalhado nas escolas. Assim, é possível que educadores tomem iniciativas para sensibilizar seus estudantes para um papel mais ativo na sociedade no combate ao vetor da Chikungunya.
\end{abstract}

Palavras-chave: Chikungunya; Educação em Saúde; Epidemiologia; Macaé; Vetores.

\section{Chikungunya and its cross-cutting approach to teaching natural sciences}

\begin{abstract}
The CHIKV virus, which promotes Chikungunya disease, is transmitted by mosquitoes of the species Aedes aegypti and albopictus. These mosquitoes have a preference for hot and humid places like Brazil, which is a tropical country. With the arrival of the virus in our country, several cases of infection and deaths from the disease have been identified. Since then, the Ministry of Health together with other State Secretariats, such as the Ministry of Education, promote strategies to combat the disease vector. In this aspect, the schools collaborate with educational strategies that also promote the combat of the vector of Chikungunya. This research aimed to evaluate the knowledge of the students of the third year of high school of three state schools in Macaé/RJ about the Chikungunya theme. It was developed in three public schools of the city of Macaé, with the application of a questionnaire composed of 8 questions that approached aspects of specific knowledge about Chikungunya. A total of 65 students were interviewed. About $44 \%$ of the students correctly identified the pathogenic agent of Chikungunya, $88 \%$ correctly identified the vector transmitting the disease, $81 \%$ know the processes that contribute to the proliferation of the vector. On the other hand, about $48 \%$ do not recognize the main symptoms of the disease, $23 \%$ do not know that the disease can cause death and $47 \%$ do not recognize the phase in which the vector transmits the disease. We concluded that, although the interviewed students presented knowledge about some subjects, they still have a gap in some points about the Chikungunya subject, being necessary that the subject be better worked in the schools. Thus, it is possible that educators take initiatives to sensitize their students to a more active role in society in the fight against the Chikungunya vector.
\end{abstract}

Keywords: Chikungunya; Health education; Epidemiology; Macaé; Vectors.

Topic: Educação em Saúde

Reviewed anonymously in the process of blind peer
Received: 22/10/2020

Approved: $24 / 01 / 2021$
Jonatha Anderson Fraga Egidio (it)

Universidade Estadual do Norte Fluminense Darcy Ribeiro, Brasil http://lattes.cnpq.br/9424766036531541 http://orcid.org/0000-0003-2212-877X

jonathaafegidio@gmail.com

Willian Rodrigues da Costa Marinho

Universidade Federal do Rio de Janeiro, Brasil

http://lattes.cnpq.br/8236809033603146

will.bio2016@gmail.com

Graziele Fonseca de Sousa (iD

Universidade Federal do Rio de Janeiro, Brasil

http://lattes.cnpq.br/5573207073284061

http://orcid.org/0000-0003-2948-2229

sousa.graziele@gmail.com a

DOI: 10.6008/CBPC2318-3047.2021.001.0009
Referencing this:

EGIDIO, J. A. F.; MARINHO, W. R. C.; SOUSA, G. F.. Chikungunya e sua abordagem transversal no ensino de ciências naturais. Educationis, v.9, n.1, p.70-77, 2021. DOI: http://doi.org/10.6008/CBPC23183047.2021.001.0009 


\section{INTRODUÇÃO}

Desde a chegada da Chikungunya no Brasil, o Ministério da Saúde (MS) tem promovido ações de combate à doença visto que ela tem causado sérios problemas econômicos e sociais para nosso país. Essa ação de combate envolve a contratação de Agentes de Combate às Endemias (ACE) que realizam vistorias nas residências em busca de foco do mosquito vetor da doença, propagandas em jornais e na televisão que estimulam a atuação da sociedade na eliminação do vetor (BRITO, 2018; TEICH et al., 2017; SOUZA et al., 2017).

A Chikungunya é uma doença causada por um vírus de RNA, conhecido como CHIKV. Ela é transmitida por mosquitos das espécies Aedes aegypti e Aedes albopictus enquanto as fêmeas destas espécies realizam repasto sanguíneo em humanos (OLIVEIRA et al., 2015; LANCIOTTI et al., 2014; SILVA, 2008).

As espécies vetoras da Chikungunya encontram no Brasil um ambiente ideal para se estabelecer, elas possuem preferência por locais quentes e úmidos, típico de clima tropical, além disso nossos centros urbanos estão em condições precária e com uma massa populacional densa, sendo esses aspectos que colaboram com sua proliferação (TAUIL, 2014; GONÇALVES NETO et al., 2004).

O vírus é incapaz de causar prejuízo para o vetor, apenas após o período de incubação que dura cerca de 10 dias é que o vetor tem capacidade de transmitir o vírus CHIKV. Devido ao hábito exclusivo dentro dessas espécies de alimentar-se de sangue para nutrir seus ovos, apenas as fêmeas adultas são capazes de transmitir o vírus causador da Chikungunya (SES, 2020; SILVA, 2008).

Quando diagnosticado com Chikungunya, o paciente pode apresentar os seguintes sintomas: febre alta, dores intensas nas juntas bilaterais, pele e olhos avermelhados, dores pelo corpo, dor de cabeça, náuseas e vômitos, em casos mais severos pode provocar o óbito (MOGAMI et al., 2017). Após a chegada da Chikungunya no Brasil em 2014, quando foram registrados cerca de 2.772 casos da doença., o MS iniciou suas ações de combate contra o vetor da Chikungunya (TORRES et al., 2019; HONÓRIO et al., 2015).

Visto que a doença não possui cura, é necessário realizar medidas de combate contra seu vetor. A atuação dos ACE na eliminação dos focos de mosquitos encontrados nas residências, comércios e terrenos baldios, a participação destes em eventos escolares para divulgação de informações sobre o combate e a apresentação de propagandas na TV a respeitos das medidas individuais que cada cidadão pode realizar em sua moradia para evitar a proliferação do vetor, são algumas das medidas tomadas pelo MS para controlar a proliferação do vetor (MANIERO et al., 2016; ALENCAR et al., 2008).

Além dessas medidas de combate aos vetores da Chikungunya, o MS uniu-se ao MEC para introduzir nas escolas atividades que sensibilizem os participantes para uma atuação direta no combate às endemias. De fato, o espaço escolar é reconhecido como meio para desenvolver a socialização dos estudantes e também na sua formação social e ambiental (NARCIZO, 2009). A metodologia transversal de ensino é uma boa maneira de abordar medidas de combate as arboviroses, em especial a Chikungunya, através da Educação em Saúde e Ambiental inseridas dentro do ensino de Ciências e Biologia durante a educação básica (OLIVEIRA, 2006). 
Os Parâmetros Curriculares Nacional (PCNs) destacam, para o ensino de Ciências e Biologia que essas atividades tragam aos estudantes a responsabilidade de serem agentes transformadores do mundo que vivem, elas devem ser capazes de se perceberem atuantes no que diz respeito a "à preservação e à implementação da saúde individual, coletiva e do ambiente" (BRASIL, 2006; BRASIL, 1997).

Para atingir os objetivos previsto para as atividades que se deseja desenvolver no espaço escolar relacionadas ao tema Chikungunya, é muito importante que haja um planejamento das atividades envolvidas, os objetivos que se pretendem alcançar, delimitar os procedimentos a serem realizados durante a atividade e como pode ser realizada uma avaliação da atividade, ou seja, se os objetivos foram atingidos ou não. Acima de tudo, essa atividade deve ser capaz de sensibilizar e conscientizar o estudante de seu papel no combate a Chikungunya.

Acredita-se que em algum momento da educação básica a Chikungunya, enquanto arbovirose de importância na saúde pública, esteja sendo abordada nas escolas públicas para estimular a conscientização dos estudantes em seu papel no combate à doença. Assim, nosso objetivo é avaliar o conhecimento dos estudantes do terceiro ano do ensino médio de três colégios estaduais do município de Macaé/RJ sobre o tema Chikungunya.

\section{METODOLOGIA}

A pesquisa foi desenvolvida em três colégios da rede pública no município de Macaé, são ele: Colégio Estadual Luiz Reid, Colégio Estadual 1 de Maio e Colégio Estadual Matias Neto. As instituições estão localizadas no Centro da cidade, região está que possui um fluxo populacional denso devido à zona comercial estabelecida na região. Os colégios também apresentam uma circulação elevada de estudantes que residem em diversos bairros do município.

A avaliação se deu por meio de um questionário aplicado para uma turma do terceiro ano do ensino médio de cada colégio, escolhida aleatoriamente. Antes de entrar na sala de aula para aplicar o questionário foi necessário obter a autorização da direção da instituição e dos professores regentes da turma no horário em que o questionário foi aplicado.

Na sala de aula foi solicitado que os estudantes que desejassem participar da pesquisa respondessem o questionário de caneta esferográfica azul, sem nenhum tipo de consulta e ao terminar de responder deveria devolver o formulário para ser guardado. Nenhum estudante se recusou em participar da pesquisa.

O questionário foi impresso em uma folha A4 e composto por 8 perguntas de múltipla escolha. Ele foi elaborado com base nas informações básicas sobre o tema Chikungunya que se julga relevante e adequado para o conhecimento de jovens estudantes.

\section{RESULTADOS}

A pesquisa foi realizada com 65 estudantes no total, sendo eles: 25 estudantes do Colégio Estadual Luiz Reid, 22 estudantes do Colégio Estadual Primeiro de Maio e 18 estudantes do Colégio Estadual Matias Neto (Tabela 1). 
Tabela 1: Percentual de estudantes do terceiro ano do ensino médio entrevistados nos Colégios Estaduais Luiz Reid, 1 de Maio e Matias Neto.

\begin{tabular}{|l|l|l|}
\hline Nome do Colégio & Número de entrevistados & Percentual de entrevistados \\
\hline Colégio Estadual Luiz Reid & 25 & $38 \%$ \\
\hline Colégio Estadual Primeiro de Maio & 22 & $34 \%$ \\
\hline Colégio Estadual Matias Neto & 18 & $\mathbf{2 8 \%}$ \\
\hline Total de estudantes entrevistados & $\mathbf{6 5}$ & $\mathbf{1 0 0 \%}$ \\
\hline
\end{tabular}

A primeira pergunta apresentada no questionário foi ‘Quem é o agente patogênico causador da Chikungunya?'. Os resultados obtidos foram os seguintes, entre $27 \%$ e $64 \%$ dos estudantes identificaram corretamente o vírus como sendo o agente patogênico causador da Chikungunya (Figura 1). Por outro lado, não podemos deixar de nos atentar ao fato de que entre $8 \%$ e $39 \%$ dos estudantes ainda apontam protozoários e bactérias como agentes patogênicos da Chikungunya e outros nem sabem responder.

Na figura 2 observamos que mais de $80 \%$ dos estudantes entrevistados apontaram corretamente o mosquito com sendo o vetor transmissor da Chikungunya.

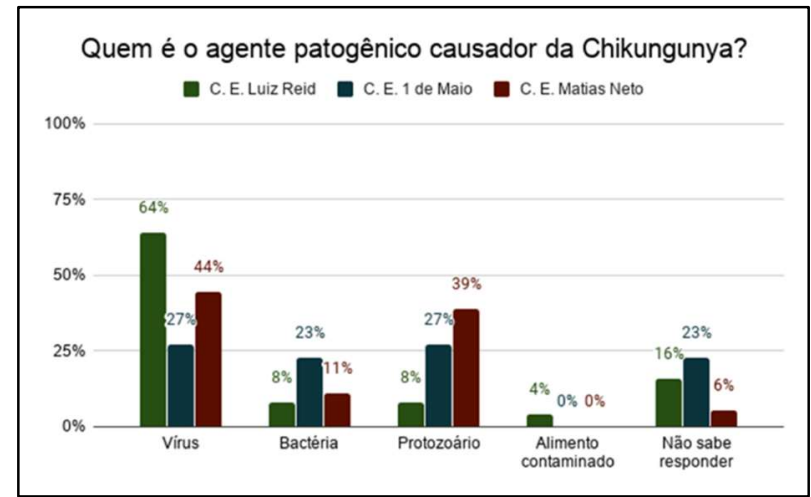

Figura 1: Percentual de respostas dos estudantes entrevistados nos Colégios Estaduais Luiz Reid, 1 de Maio e Matias Neto a pergunta 'Quem é o agente patogênico causador da Chikungunya?'.

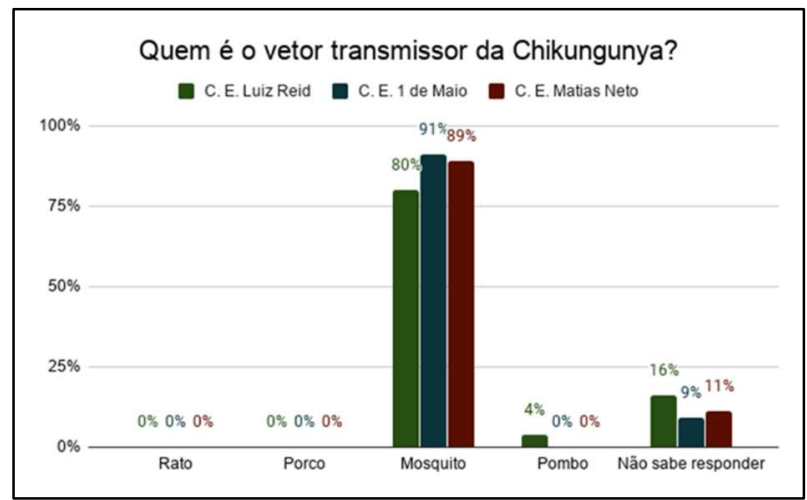

Figura 2: Figura 5: Percentual de respostas dos estudantes entrevistados nos Colégios Estaduais Luiz Reid, 1 de Maio e Matias Neto a pergunta 'Quem é o vetor transmissor da Chikungunya?'.

A terceira pergunta abordada no questionário os entrevistados deveriam sinalizar a melhor resposta para a pergunta 'O que contribui para a proliferação do vetor do Chikungunya?'. Na figura 3 observamos que mais de $68 \%$ dos estudantes entrevistados sabem identificar corretamente os fatores que contribuem para a proliferação do vetor da Chikungunya.

Outra pergunta abordada no questionário era sobre os principais sintomas da doença. Até o presente momento é possível identificar os principais sintomas da doença, sendo eles: febre, dores intensas nas juntas em geral bilaterais, pele e olhos avermelhados, dores pelo corpo, dor de cabeça, náuseas e vômitos. Ao passo que se conhece os principais sintomas o indivíduo diagnosticado com a doença procura os melhores tratamentos possíveis de acordo com a prescrição médica, além disso tem o cuidado necessário para não agravar o estado de saúde. Analisando os resultados da figura 4, observamos que no C. E. Matias Neto $78 \%$ dos estudantes entrevistados conhecem os principais sintomas da doença, por outro lado, no C. E. Luiz Reid 48\% e no C. E. 1 de Maio 64\% dos estudantes não conseguem identificar esses sintomas. 


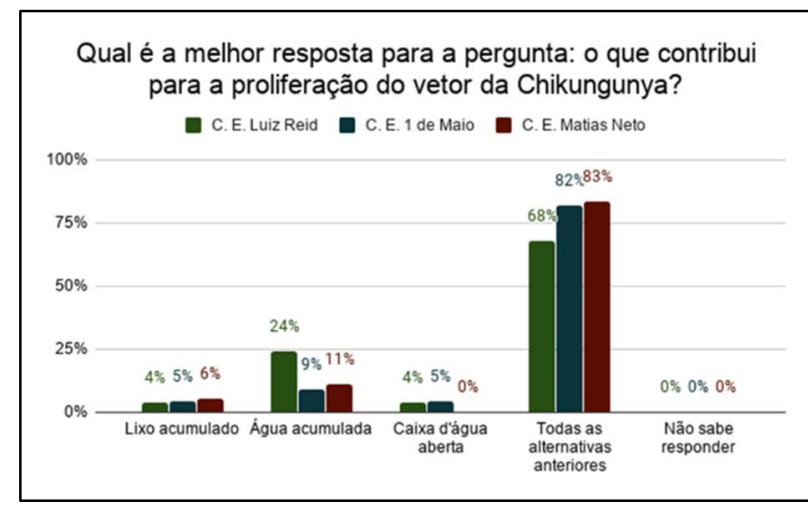

Figura 3: Percentual de respostas dos estudantes entrevistados nos Colégios Estaduais Luiz Reid, 1 de Maio e Matias Neto a pergunta 'Qual é a melhor resposta para a pergunta: que contribui para a proliferação do vetor da Chikungunya?'.

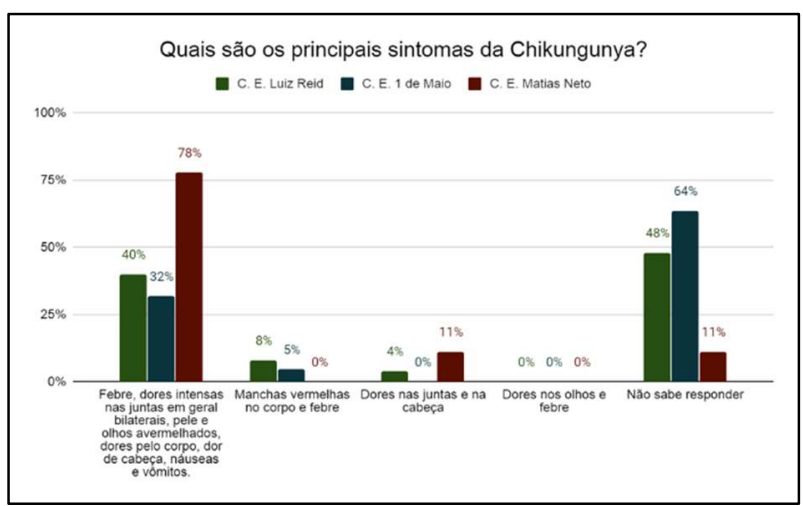

Figura 4: Percentual de respostas dos estudantes entrevistados nos Colégios Estaduais Luiz Reid, 1 de Maio e Matias Neto a pergunta 'Quais são os principais sintomas da Chikungunya?'.

Outra pergunta do questionário solicitava que os estudantes identificassem o(s) vetor(es) transmissor(es) da Chikungunya, mais de $41 \%$ dos entrevistados identificaram corretamente as espécies $\mathrm{A}$. aegypti e A. albopictus como sendo os transmissores da Chikungunya, entretanto, um percentual entre $22 \%$ e 32\% não soube responder essa pergunta (Figura 5).

Quando questionados sobre a fase em que o vetor transmite a Chikungunya o resultado mostra que mais de $39 \%$ dos entrevistados responderam incorretamente (Figura 6).

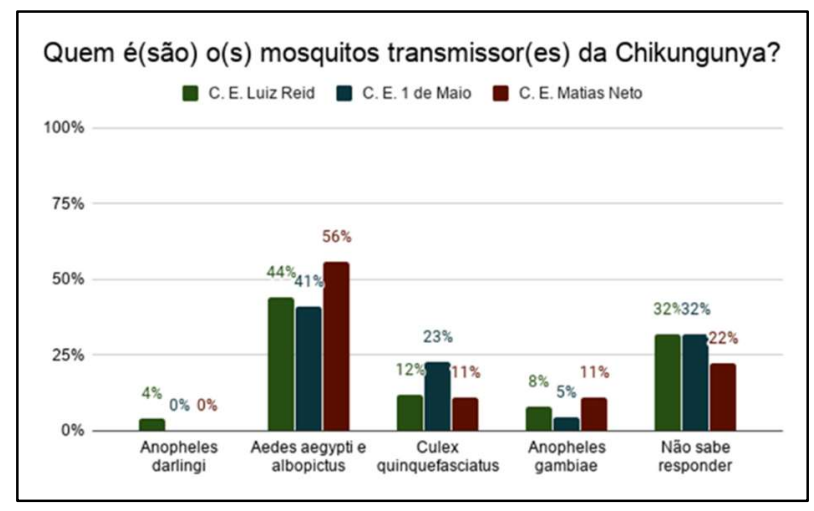

Figura 5: Percentual de respostas dos estudantes entrevistados nos Colégios Estaduais Luiz Reid, 1 de Maio e Matias Neto a pergunta 'Qual é a melhor resposta para a pergunta: que contribui para a proliferação do vetor da Chikungunya?'.

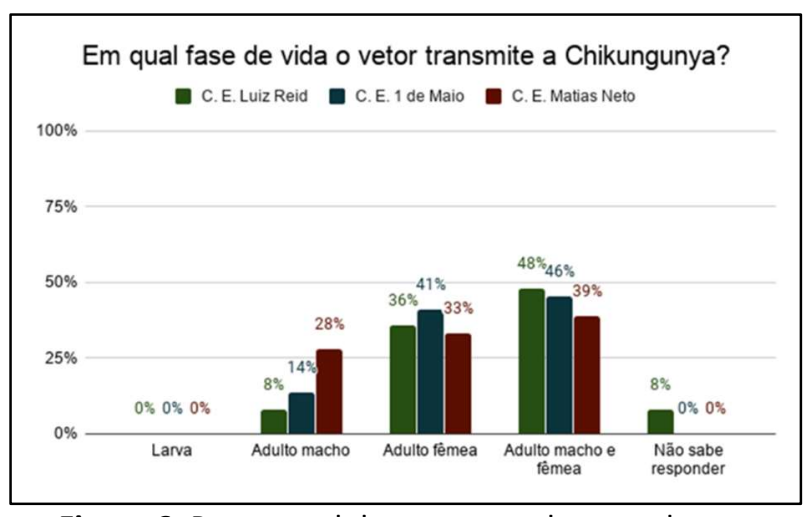

Figura 6: Percentual de respostas dos estudantes entrevistados nos Colégios Estaduais Luiz Reid, 1 de Maio e Matias Neto para a pergunta 'Em qual fase o vetor transmite o Chikungunya?'.

O questionário perguntou aos estudantes entrevistados se a Chikungunya poderia ser prevenida, na figura 7 observamos que mais de $76 \%$ dos entrevistados concordam que essa doença pode ser prevenida, os restantes dos entrevistados não concordam ou não sabem responder.

Outra pergunta abordada no questionário era se a CHIKV pode causar a morte, analisamos que mais de $59 \%$ dos estudantes entrevistados sabem que a Chikungunya pode causar a morte de pessoas infectadas, no C. E. Luiz Reid $88 \%$ dos estudantes acertaram essa questão. Entretanto, no C. E. 1 de Maio $18 \%$ dos estudantes entrevistados responderam que a Chikungunya não causa morte e $28 \%$ dos estudantes entrevistados no C. E. Matias Neto não souberam responder, talvez porque não conhecem alguém que tenha morrido em decorrência da Chikungunya (Figura 8). 


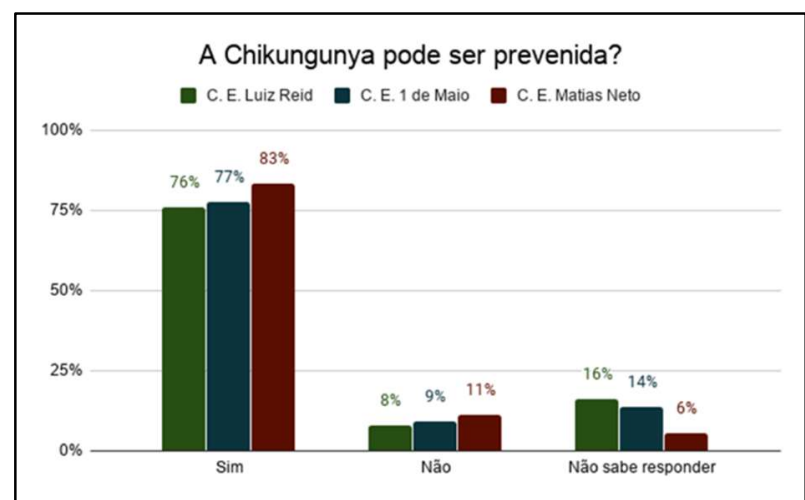

Figura 7: Percentual de respostas dos estudantes entrevistados nos Colégios Estaduais Luiz Reid, 1 de Maio e Matias Neto para a pergunta 'A Chikungunya pode ser prevenida?'.

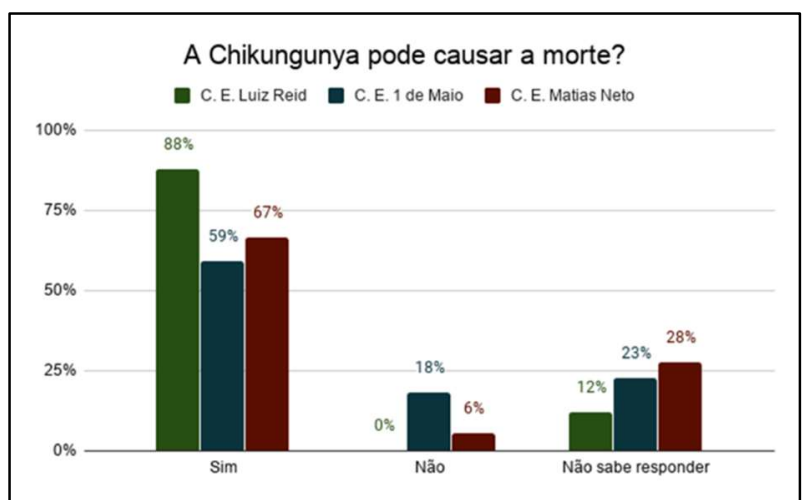

Figura 8: Percentual de respostas dos estudantes entrevistados nos Colégios Estaduais Luiz Reid, 1 de Maio e Matias Neto para a pergunta 'A Chikungunya pode causar a morte?'.

\section{DISCUSSÃO}

Quando os estudantes sinalizam erroneamente protozoário e bactéria como agentes causadores da Chikungunya, percebe-se a necessidade de intensificar ações de combate às endemias dentro do espaço escolar, como sugere Santos et al. (2017). Essas ações educativas são importantes para a prevenção da Chikungunya. É o que indica Silva (2018) quando afirma que essas abordagens possuem influência sobre o processo de conscientização e sensibilização dos estudantes envolvidos. É possível notar esse fato quando observamos que a maioria dos estudantes identificam corretamente o mosquito como sendo o vetor transmissor da doença.

Conhecer os métodos de combate permite que os estudantes atuem diretamente na eliminação do foco do mosquito em sua residência. O ambiente escolar é um local ideal para a realização de feiras de ciências, gincanas e outros projetos que ensinam os estudantes processos que contribuem para a proliferação do vetor e as maneiras pelas quais ele pode eliminar os criadouros de mosquitos de maneira segura, dessa forma podemos observar um dado positivo na figura 3 , ela mostra que a maioria dos estudantes compreendem os aspectos citados anteriormente.

Não conhecer os principais sintomas da doença, as principais características e o ciclo de vida do mosquito vetor, são fatores que podem atrapalhar a campanha de combate, à medida que quando se conhece os sintomas da doença o paciente diagnosticado pode procurar o melhor tratamento e quando se conhece a biologia do vetor transmissor da doença busca-se as melhores estratégias que inibem a proliferação do mesmo de forma direta (SANTOS, 2018; HONÓRIO et al., 2015).

Por fim, observa-se que os estudantes compreendem que a doença pode levar ao óbito e que a mesma pode ser prevenida. Como sinaliza Souza (2016), esse conhecimento pode amenizar os impactos da doença na sociedade à medida que este mesmo conhecimento pode levar as os estudantes a tomarem algumas medidas de combate ao mosquito, como evitar deixar água parada, limpar recipientes que podem acumular água e jogar o lixo em local apropriado. 


\section{CONCLUSÕES}

Observa-se que ao serem questionados sobre o vetor transmissor da Chikungunya, as contribuições para a proliferação do vetor, a possibilidade de doença ser prevenida e se a doença pode causar o óbito, os estudantes entrevistados apresentaram um bom desempenho. Entretanto, ao serem questionados sobre o agente patogênico causador da Chikungunya, os principais sintomas da doença, as espécies transmissoras e a fase de vida em que o vetor transmite a doença, os estudantes entrevistados não apresentaram um bom desempenho.

Apesar de possuírem algum conhecimento acerca da doença, percebemos que os mesmos possuem defasagem em alguns pontos, sendo necessário que os educadores voltem a discutir sobre a Chikungunya em outros momentos e estejam sempre empenhados em melhorar os métodos de abordagem para que seja possível sensibilizar os estudantes sobre a importância que todos temos no combate aos vetores da doença.

\section{REFERÊNCIAS}

ALENCAR, C. H. M.; ALBUQUERQUE, L. M.; AQUINO, T. M. F.; SOARES, C. B.; RAMOS JÚNIOR, A. N.; LIMA, J. W. O.; PONTES, R. J. S.. Potencialidades do Aedes albopictus como vetor de arboviroses no Brasil: um desafio para a atenção primária. Revista de Atenção Primária à Saúde, v.11, n.4, 2008.

BRASIL. Ministério da Educação. Lei de Diretrizes. Orientações curriculares para o ensino médio. Volume 2Ciências da natureza, matemática e suas tecnologias. Secretaria de Educação Básica. Brasília: MEC, 2006.

BRASIL. Secretaria de Educação Fundamental. Parâmetros Curriculares Nacionais: ciências naturais, Brasília. MEC/SEF. 1997.

BRITO, P. T.. A percepção dos agentes comunitários de saúde e dos agentes de combate às endemias sobre $a$ comunicação de risco das arboviroses emergentes no Brasil: Dengue, Zika e Chikungunya. 2018.

GONÇALVES NETO, V. S.; REBÊLO, J. M. M.. Aspectos epidemiológicos da Dengue no município de São Luis, Maranhão, Brasil, 1997- 2002. Cadernos de Saúde Pública, v.20, p.1427-1431, 2004.

HONÓRIO, N. A.; CÂMARA, D. C. P.; CALVET, G. A.; BRASIL, P.. Chikungunya: uma arbovirose em estabelecimento e expansão no Brasil. Cadernos de Saúde Pública, v.31, n.5, p.906-908, 2015. DOI: http://doi.org/10.1590/0102311XPE020515

LANCIOTTI, R. S.; VALADERE, A. M.. Movimento transcontinental do vírus do genótipo asiático chikungunya. Doenças Infecciosas Emergentes, v.20, n.8, p.1400, 2014.

MANIERO, V. C.; SANTOS, M. O.; RIBEIRO, R. L.; OLIVEIRA, P. A. C.; SILVA, T. B.; MOLERI, A. B.; MARTINS, I. R.; LAMAS, C. C.; CARDOZO, S. V.. Dengue, Chikungunya e Zika vírus no Brasil: situação epidemiológica, aspectos clínicos e medidas preventivas. Almanaque Multidisciplinar de Pesquisa, v.1, n.1, 2016.
MOGAMI, R.; VAZ, J. L. P.; CHAGAS, Y. F. B.; TOREZANI, R. S.; VIEIRA, A. A.; KOIFMAN, A. C. B.; BARBOSA, Y. B.; ABREU, M. M.. Ultrasound of ankles in the diagnosis of complications of Chikungunya fever. Radiologia Brasileira, v.50, n.2, p.71-75, 2017. DOI: http://doi.org/10.1590/0100-3984.2016.0221

NARCIZO, K. R. S.. Uma análise sobre a importância de trabalhar educação ambiental nas escolas. REMEA - Revista Eletrônica do Mestrado em Educação Ambiental, v.22, 2009.

OLIVEIRA, A. L.. Educação ambiental: concepções e práticas de professores de ciências do ensino fundamental.

Dissertação (Mestrado) - Universidade Estadual de Maringá, Maringá, 2006.

OLIVEIRA, C. S.; COSTA, P. F.. Risco do Chikungunya para o Brasil. Rev. Saúde Pública, v.49, p.58, 2015.

SANTOS, F. J.. Saúde pública e aedes aegypti na escola José Gonçalves de Queiroz. 2018.

SANTOS, M. E. M.; BATISTA, W. S.; OLIVEIRA, J. V.; JANSEN, I. C. C.; SANTOS, K. F. S.; SANTOS, E. C. R.. Ações educativas para o combate ao mosquito Aedes aegypti em uma escola da região metropolitana de São Luís. Revista Caderno Pedagógico, v.14, n.1, 2017. DOI: http://dx.doi.org/10.22410/issn.19830882.v14i1a2017.1317

SES. Informe técnico sobre Chikungunya SES/GO: Preparação e Resposta à Introdução do Vírus Chikungunya no Brasil. Goiânia: SES, 2020.

SILVA, D. T. F. N.. A importância de ações de educação socioambiental na escola como mecanismo de combate a proliferação dos vetores de arboviroses. 2018.

SILVA, J. S.. The dengue fever in Brazilan d combat Dengue fevertothe Aedes aegypti: of the trye radication to control policies. Hygeia, v.4, n.6, 2008.

SOUZA, L. J.. Dengue, Zika e Chikungunya: diagnóstico, 
tratamento e prevenção. Rubio, 2016.

TAUIL, P. L.. Condições para a transmissão da febre do vírus Chikungunya. Epidemiologia e Serviços de Saúde, v.23, p.773-774, 2014.

TEICH, V.; ARINELLI, R.; FAHHAM, L.. Aedes aegypti e sociedade: o impacto econômico das arboviroses no Brasil. JBES - Jornal Brasileiro de Economia da Saúde, v.9, n.3, 2017.

TORRES, S.; PRADA, Y. L. C.; ROJAS, C. A.. Conhecendo o Aedes Aegypti e Aedes Albopictus, os mosquitos dos vários vírus. 2019.

A CBPC - Companhia Brasileira de Produção Científica (CNPJ: 11.221.422/0001-03) detém os direitos materiais desta publicação. Os direitos referem-se à publicação do trabalho em qualquer parte do mundo, incluindo os direitos às renovações, expansões e disseminações da contribuição, bem como outros direitos subsidiários. Todos os trabalhos publicados eletronicamente poderão posteriormente ser publicados em coletâneas impressas sob coordenação da Sustenere Publishing, da Companhia Brasileira de Produção Científica e seus parceiros autorizados. Os (as) autores (as) preservam os direitos autorais, mas não têm permissão para a publicação da contribuição em outro meio, impresso ou digital, em português ou em tradução. 